\title{
@@- OPENACCESS EFFICACY OF RECTAL MISOPROSTOL VS INTRAVENOUS check for updates OXYTOCIN IN PREVENTING POSTPARTUM HEMORRHAGE FOLLOWING ELECTIVE CAESAREAN SECTION
}

Department of Obstretic \& Gynaecology, Lady Reading Hospital (Medical Teaching Hospital), Peshawar-Pakistan

Address for correspondence: Heera Urooj

Department of Obstretic \& Gynaecology, Lady Reading Hospital (Medical Teaching Hospital), Peshawar-Pakistan

E-mail:

heerasheikh05@gmail.com

Date Received:

September, $18^{\text {th }} 2020$

Date Revised:

December, 24 $4^{\text {th }} 2021$

Date Accepted:

December, $27^{\text {th }} 2021$
This article may be cited as Shah M, Urooj H, Shah S, Rahim R. Efficacy of rectal misoprostol vs intravenous oxytocin in preventing postpartum hemorrhage following elective caesarean section. J Postgrad Med Inst 2021;35(3):131-5. https://doi.org/10.54079/ jpmi.35.3.2780.

\author{
Mehtab Shah, Heera Uroojª, Shazma Shah, Rehana Rahim
}

\section{ABSTRACT}

Objective: To compare the efficacy of rectal misoprostol with intravenous oxytocin in prevention of postpartum hemorrhage (PPH) in elective cesarean section (CS) operation.

Methodology: This randomized controlled trial was conducted in the Department of Obstetrics \& Gynecology Department, Lady Reading Hospital, Peshawar. A total of 334 women undergoing elective CS were recruited in the study through consecutive sampling and randomly allocated to misoprostol group (group A) and IV oxytocin group (Group B). Follow up was done to determine the mean blood loss in both groups to determine the efficacy in terms of presence or absence of postpartum hemorrhage.

Results: The mean age in group A was $31.2 \pm 6.8$ years compared to $30 \pm 6.2$ years in group B. The mean blood loss in group A was $776 \pm 285.7 \mathrm{ml}$, while in group B it was $817 \pm 1318 \mathrm{ml}$. Efficacy of rectal misoprostol was $83.8 \%$ as compared to $74.9 \%$ for I/V Oxytocin with a significant p-value of 0.043 .

Conclusion: Rectal misoprostol in women prepared for elective cesarean section show better efficacy in terms of PPH prevention as compared to IV oxytocin.

Key Words: Post-partum hemorrhage; Misoprostol; Oxytocin; Cesarean section; Obesity.

\section{INTRODUCTION}

Postpartum hemorrhage is a life threatening obstetric emergency, accounting for a quarter of pregnancy related deaths, estimated at more than half a million annually. ${ }^{1}$ Up to $5 \%$ of deliveries are complicated by postpartum hemorrhage in both developed and developing countries. ${ }^{2}$

Postpartum hemorrhage can be primary or secondary. Primary postpartum hemorrhage is defined as blood loss amounting to or more than $500 \mathrm{ml}$ from genital tract within 24 hours after spontaneous vaginal delivery. ${ }^{3}$ Uterine atony is the most common cause, responsible for $75-90 \%$ of cases. ${ }^{4,5}$ Secondary postpartum hemorrhage is abnormal or increased bleeding from genital tract between 24 hours to 12 weeks of childbirth. ${ }^{6}$ Risk factors for postpartum hemorrhage include multiple pregnancy, fetal macrosomia, failure to progress in second stage of labor, prolonged third stage of labor, retained placenta, placenta accreta, episiotomy, perineal laceration and general anesthesia. ${ }^{6}$ Complications of postpartum hemorrhage include maternal anemia, infection, shock, renal tubular necrosis, consumption coagulopathy, prolonged hospital stay, psychological sequelae and complications of blood transfusion.

Caesarean section is the most common surgical procedure performed on pregnant women. ${ }^{7}$ In case of caesarean section, postpartum hemorrhage is defined as blood loss greater than $1000 \mathrm{ml}^{7,8}$ The standard uterotonics used are oxytocin or syntometrine. ${ }^{9}$ The efficacy of oxytocin in reducing frequency of postpartum hemorrhage is well established. ${ }^{10}$ For women delivering by caesarean section, $5 \mathrm{IU}$ of oxytocin by slow intravenous injection is recommended by RCOG ${ }^{6}$ Oxytocin has rapid onset of action but the drawbacks of oxytocin are its short half-life and instability at room temperature. ${ }^{9}$ In case of caesarean section, it may result in maternal hypotension and tachycardia. ${ }^{11}$

Misoprostol, another uterotonic agent, is a Prostaglandin E1 analogue. It binds selectively to EP2/EP3 receptors in myometrium. ${ }^{12}$ It's advantages over oxytocin include its low cost, thermostability, long shelf life and easy administration. Shivering and pyrexia are some of the common side effects with use of misoprostol, which are less marked with rectal route of adminis- 
tration. ${ }^{12}$ Some studies show that during caesarean section, misoprostol is effective when it come to comparison with oxytocin in reducing hemorrhage. ${ }^{8}$

A study conducted in Iran showed that the blood loss with misoprostol was $578 \pm 185$ $\mathrm{ml}$ and with oxytocin, it was $620 \pm 213 \mathrm{ml}$ $(p=0.39)$. Shivering was more with misoprostol while respiratory distress was common in oxytocin group. ${ }^{8}$ In another study conducted by Mirteimouri et al, bleeding to the amount of more than $500 \mathrm{cc}$ was significantly more in oxytocin than misoprostol group (33\% vs. $19 \%$; $p=0.005$ ). So oxytocin was effective in $67 \%$ cases while misoprostol was effective in $81 \%$ cases. $^{13}$

In this study, we planned to compare the efficacy of rectal misoprostol given before induction of anesthesia and intravenous oxytocin in prevention of postpartum hemorrhage in patients undergoing elective caesarean section, as no such study has been conducted in our population for the last five years so this study will provide us the latest and updated information regarding efficacy of rectal misoprostol in prevention of postpartum hemorrhage in elective cesarean section.

\section{METHODOLOGY}

This randomized controlled trial was conducted in the Department of Gynae and Obstetrics, Lady Reading Hospital Peshawar after taking ethical approval from IREB, LRH from 29 $9^{\text {th }}$ April 2019 to $29^{\text {th }}$ October 2019 with a sample size of 334 in total (Figure 1). History, demographic data, clinical investigation were performed. All the patients fulfilling the inclusion criteria like singleton pregnancy, age 15 to 40years, period of gestation $>37$ weeks and parity $<5$ were divided in two groups on the basis of lottery method (Random allocation). Patients in Group A received 800ug rectal misoprostol (RM) just before giving anesthesia and pa- tients in Group B received 5 IU intravenous oxytocin (IVO) soon after delivery of baby. All the patients were assessed for postpartum hemorrhage within 6 hours, 12 hours and 24 hours. Postpartum hemorrhage in caesarean section was considered positive if the blood loss was more than $1000 \mathrm{ml}$ within 24 hours of childbirth. Surgical gauzes was weighed before and after soaked with blood and the difference was noted, 1gm was taken as $1 \mathrm{ml}$. All the procedures were conducted by supervisory consultant having at least 5 years of experience.

All information like age, parity, period of gestation, obesity, diabetes mellitus, and hypertension was recorded on the pre design proforma. Data was analyzed using SPSS version 21. Quantitative variables like age, parity, period of gestation, blood loss were described as mean and standard deviation. Frequency and percentage was computed for categorical variables like obesity, diabetes mellitus, hypertension and efficacy. Comparison of efficacy between two groups was conducted and chi square test was applied in which $P$ value $\leq 0.05$ was considered as significant value.

\section{口ESULTS}

The mean age of the whole study sample was $30.6 \pm 6.5$ years. The difference of mean age between both groups was statistically not significant (p 0.109). About $27.5 \%$ of women in group A were primigravida as compared to $34.7 \%$ in group B (p 0.156), $43.7 \%$ in group $A$ were multiparous as compared to $49.7 \%$ in group B (p 0.273). In about $12.6 \%$ of patient from group $A$, there was history of previous CS, and $13.8 \%$ in group $B$ (p 0.746), 32.9\% in group A were obese as compared to $25.1 \%$ in group $B$ ( $p$ 0.117 ). As per diabetes is concerned, $24 \%$ in group A were diabetic as compared to $21 \%$ in group $B(p 0.512)$. In history of hypertension (HTN) 21.6\% in group A had history of HTN as compared to $28.1 \%$ in group $B$ ( $p$
0.164).

All patients were subjected to rectal misoprostol (RM) or intravenous oxytocin (IVO) as per initial treatment allocation and dosage according to methodology. The efficacy was measured in terms of mean blood loss. On follow up, the mean blood loss in RM group was $776 \pm 285.7 \mathrm{ml}$ while in IV0 group, it was $817 \pm 1318 \mathrm{ml}$ (p 0.206). As per operational definitions, efficacy of RM was $83.8 \%$ compared to $74.9 \%$ for IVO ( $p$ 0.043 ) as given in Table 1.

\section{DISCUSSION}

Misoprostol is a synthetic prostaglandin medication that selectively binds to EP-2/EP-3 prostanoid receptors. It has shown to be useful as a stimulant of the myometrium of the pregnant uterus. ${ }^{14}$ Furthermore, administration of misoprostol orally or rectally has been shown to be promising and effective in preventing PPH. It is seen as a preferable alternative to other ecbolic drug ${ }^{15}$. Furthermore, pharmacokinetic research investigations revealed that it has a better absorption rate when administered sublingually rather than orally or vaginally ${ }^{16}$. As a result, its sublingual administration for the prevention of PPH has been studied and proven to be efficacious. ${ }^{17}$

As a result, its sublingual administration for the prevention of PPH has been studied and proven to be efficacious. Several uterotonic medicines, including as oxytocin, ergot alkaloid, and prostaglandin, are used to prevent PPH caused by uterine atony. ${ }^{18}$ The most often utilised uterotonic agent for PPH prophylaxis is oxytocin. ${ }^{19}$ Compared to other uterotonic medicines, oxytocin is affordabe, cost effective and has a rapid onset of action. ${ }^{20}$

Several RCTs proved that misoprostol is effective in reducing blood loss but a multicenter randomized controlled trial found that in the active management of the third stage of labor, oxytocin was superior to oral misoprostol 22. Misoprostol may be inferior to oxytocin for the prevention of PPH, according to systematic evaluations of randomized controlled trials (RCTs). ${ }^{23,24}$ Misoprostol delivery also increases the risk of fever and mild shiver- 


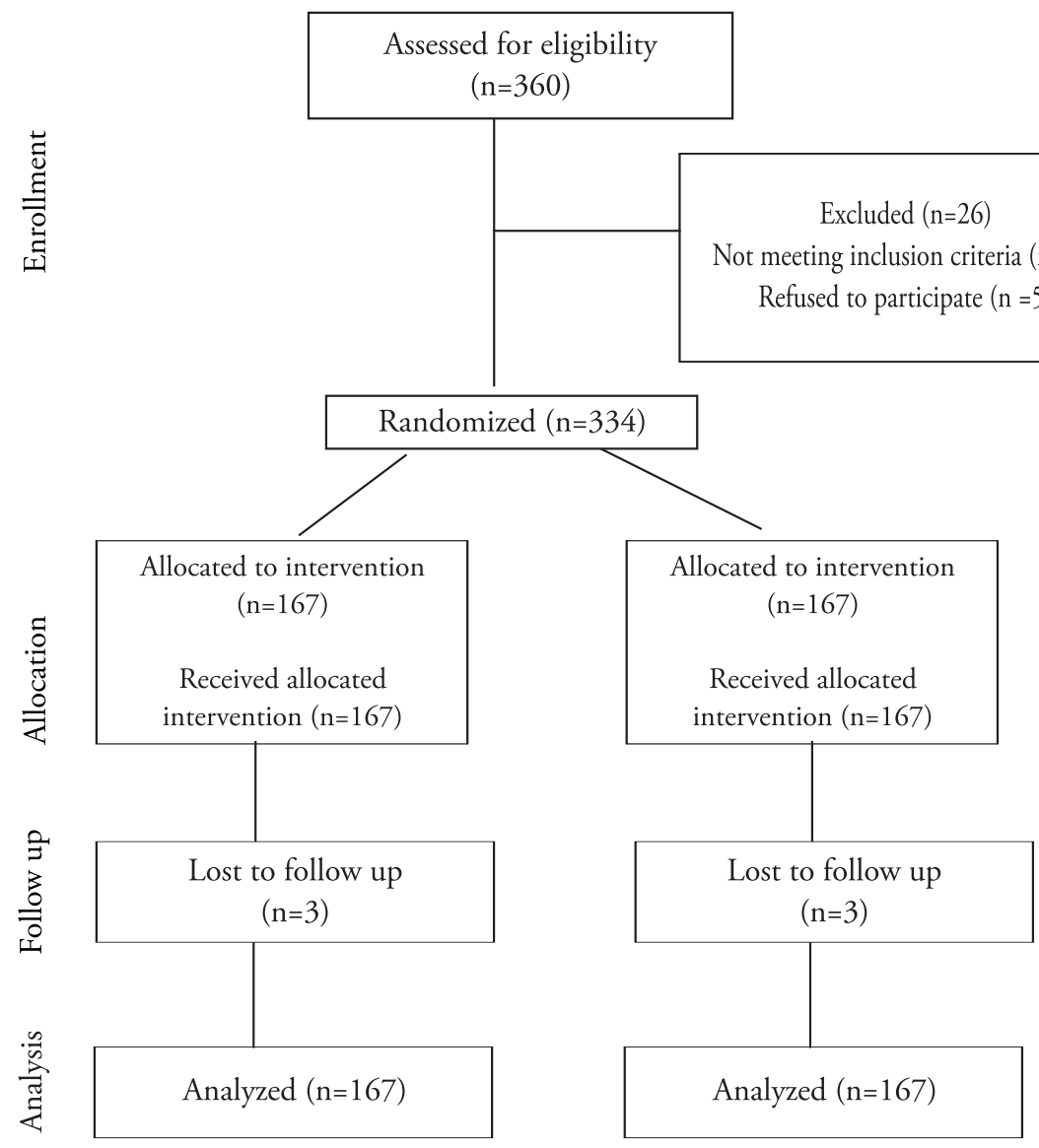

Figure 1: CONSORT diagram showing the flow of participants through each stage of the trial.

Table 1: Comparison Of Efficacy Between Both Groups ( $\mathrm{N}$ = 167 Each)

\begin{tabular}{|c|c|c|c|}
\hline \multirow{2}{*}{ Variables } & \multicolumn{2}{|c|}{ Treatment Group } & \multirow{2}{*}{ P value } \\
\cline { 2 - 3 } & Rectal Misoprostol & IV Oxytocin & \\
\hline \multirow{2}{*}{ Efficacy } & Yes & $140(83.8 \%)$ & $125(74.9 \%)$ \\
\cline { 2 - 3 } & No & $27(16.2 \%)$ & $42(25.1 \%)$ \\
\hline
\end{tabular}

ing. ${ }^{25}$ As a result, the World Health Organization (WHO) suggested using oxytocin instead of misoprostol in the prophylaxis of Postpartum hemorrhage during the third stage of labor. ${ }^{23}$

In our study, of misoprostol versus oxytocin, we found that misoprostol expressed statistically significant efficacy in terms of reduced blood loss compared to oxytocin. This conclusion contradicts the findings of a multicenter randomised trial22 conducted by the World Health Organization. During the third stage of labor, 366 females in misoprostol and 263 females in the oxytocin using patients had $1000 \mathrm{~mL}$ blood loss, showing a significant difference. Furthermore, in that trial, 1398 (15\%) females in the misoprostol category and $1002(11 \%)$ females in the oxytocin group needed extra uterotonics.

Another study showed that rectal misoprostol $(400 \mu \mathrm{g})$ when compared in a study to Syntometrine demonstrated no significant difference in the duration of the third stage of labor. ${ }^{26} \mathrm{~A}$ meta-anaysis on misoprostol in preventing postpartum hemorrahge showed that misoprostol is effective in the prevention of PPH and should be used in countries where it is the only feasible option. ${ }^{27}$ In another study, rectal misoprostol $(1000 \mu \mathrm{g})$ was given to bleeding patients, not responding to ergometrine and oxytoxin while waiting for prostaglandin F2-alpha, showed control of bleeding within 3 minutes of misoprostol administration, and did not require any further uterotonic therapy and treatment. ${ }^{28}$ This result predicts that a maximum concentration of rectally administered misoprostol may be required for the treatment and prevention of hemorrhage.

Due to small sample size, our results may have less statistical power. We recommend more randomized controlled trials preferably on larger sample sizes, involving multi-centers, to draw future recommendations for misoprostol use in the prevention of PPH.

\section{CONCLUSION}


Our study concludes that rectal misoprostol in women prepared for elective cesarean section show better efficacy as compared to intravenous Oxytocin in preventing PPH in term of blood loss.

\section{口EFERENCES}

1. Nagasree MGS, Smitha A. Misoprostol versus oxytocin in prevention of postpartum hemorrhage. Int $\mathrm{J}$ Basic and Applied Med Sci. 2015; 5(1):180- 5

2. Edhi MM, Aslam HM, Naqvi Z, Hashmi H. Post partumhaemorrhage: causes and management. BMC Res Notes. 2013; 6(1):236.

3. Mousa HA, Blum J, Abou El Senoun G, Shakur H, Alfirevic Z. Treatment for primary postpartum hemorrhage. Cochrane Database Syst Rev. 2014;(2):CD003249.

4. World Health Organization. WHO recommendations for prevention and treatment of postpartum hemorrhage. Geneva: WHO; 2012.

5. Bhutto A. Rectal misoprostol versus intravenous syntometrine in active third stage of labour in low risk women. Med Channel. 2012; 18(4):40-3.

6. Mavrides E, Allard S, Chandraharan E, Collins P, Green L, Hunt BJ, et al. Prevention and management of postpartum hemorrhage. Int J Obstet Gynecol. 2016; 124:106-49.

7. Conde A, Nieto A, Rosas A. Misoprostol to reduce intraoperative and postoperative hemorrhage during cesarean delivery: a systemic review and meta-analysis. Am J Obstet Gynecol. 2013; 209(1):40-7.

8. Fazel MR, Mansoure S, Esmaeil F. A comparison of rectal misoprostol and intravenous oxytocin on hemorrhage and homeostatic changes during cesarean section. Middle East J Anaesthesiol. 2013; 22(1):41-6.

9. Vagge DS. A comparative study to assess the efficacy and tolerability of per rectal misoprostol and intravenous oxytocin in prevention of primary postpartum haemorrhage in a tertiary care hospital. J Chem Pharm Res. 2014; 6(3):1134-40.

10. Begley CM, Gyte CM, Devane D, McGuire W, Weeks A. Active versus expectant management for women in the third stage of labour. Cochrane Database Syst Rev. 2011; 11:CD007412.

11. Dyer RA, Butwick AJ, Carvalho B. Oxytocin for labour and cesarean delivery: implications for anaesthesiologist. Curr Opin Anaesthesiol. 2011; 24:255-61.

12. Unterscheider J, Breathnach F, Geary M. Standard medical therapy for postpartum hemorrhage. In: A comprehensive textbook of postpartum hemorrhage. London: Sapiens Publishing; 2012. p. 355-60.

13. Mirteimouri M, Tara F, Teimouri B, Sakhavar N, Vaezi A. Efficacy of rectal misoprostol for prevention of postpartum hemorrhage. Iran J Pharm Res. 2013; 12(2):469-74.

14. Prendiville WJ, Elbourne D, McDonald S. Active versus expectant management in the third stage of labour. Cochrane Database Syst Rev. 2000; (3):CD000007.

15. Jackson KW, Allbert JR, Schemmer GK, Elliot M, Humphrey A, Taylor J. A randomized controlled trial comparing oxytocin administration before and after placental delivery in the prevention of postpartum hemorrhage. Am J Obstet Gynecol. 2001; 185:873-7.

16. Rizvi F, Mackey R, Barrett T, McKenna P, Geary M. Successful reduction of massive postpartum haemorrhage by use of guidelines and staff education. Int $\mathrm{J}$ Obstet Gynecol. 2004; 111:495-8.

17. Lam H, Tang OS, Lee CP. A pilot-randomized comparison of sublingual misoprostol with syntometrine on the blood loss in third stage of labor. Acta Obstet Gynecol Scand. 2004; 83:647.

18. Miller S, Lester F, Hensleigh P. Prevention and treatment of postpartum hemorrhage: new advances for low-resource settings. J Midwif Womens Health. 2004; 49:283-292.

19. Schaff EA, Dicenzo R, Fielding SL. Comparison of misoprostol plasma concentrations following buccal and sublingual administration. Contraception. 2005; 71:22-25.

20. World Health Organization. Mother baby package: implementing safe motherhood in countries. Geneva: WHO; 1998.

21. Roach MK, Abramovici A, Tita AT. Dose and duration of oxytocin to prevent postpartum hemorrhage: a review. Am J Perinatol. 2013; 30:523e8.

22. Fujimoto $M$, Takeuchi $K$, Sugimoto $M$, Maruo T. Prevention of postpartum hemorrhage by uterotonic agents: comparison of oxytocin and methylergometrine in the management of the third stage of labor. Acta Obstet Gynecol Scand. 2006; 85:1310e4.

23. Chaudhuri P, Biswas J, Mandal A. Sublingual misoprostol versus intramuscular oxytocin for prevention of postpartum hemorrhage in low- risk women. Int J Gynaecol Obstet. 2012; 116:138e42

24. Walraven G, Blum J, Dampha Y, Sowe M, Morison L, Winikoff B, et al. Misoprostol in the management of the third stage of labour in the home delivery setting in rural Gambia: a randomised controlled trial. Int J Obstet Gynaecol. 2005; 112: 1277-83.

25. Derman RJ, Kodkany BS, Goudar SS, Geller SE, Naik VA, Bellad MB, et al. Oral misoprostol in preventing postpartum haemorrhage in resource-poor communities: a randomised controlled trial. Lancet. 2006; 368:1248-53.

26. Gülmezoglu AM, Villar J, Ngoc NT, Piaggio G, Carroli G, Adetoro L, et al. WHO multicentre randomised trial of misoprostol in the management of the third stage of labour. Lancet. 2001; 358: 689-95.

27. Langenbach, C. Misoprostol in preventing postpartum hemorrhage: a 
meta-analysis. Int J Obstet Gynaecol. 2006; 92:10-8.

28. Sloan NL, Durocher J, Aldrich T, Blum J,
Winikoff B. What measured blood loss tells us bout postpartum bleeding: a systematic review. Int J Obstet Gynae- col. 2010; 117:788-800.

\section{Author's Contribution}

MS conceptualized the study, drafted the manuscript and analyzed the data, HU and SS drafted the manuscript and collected the data and RR drafted the manuscript and proof read the article. Authors agree to be accountable for all aspects of the work in ensuring that questions related to : the accuracy or integrity of any part of the work are appropriately investigated and resolved.

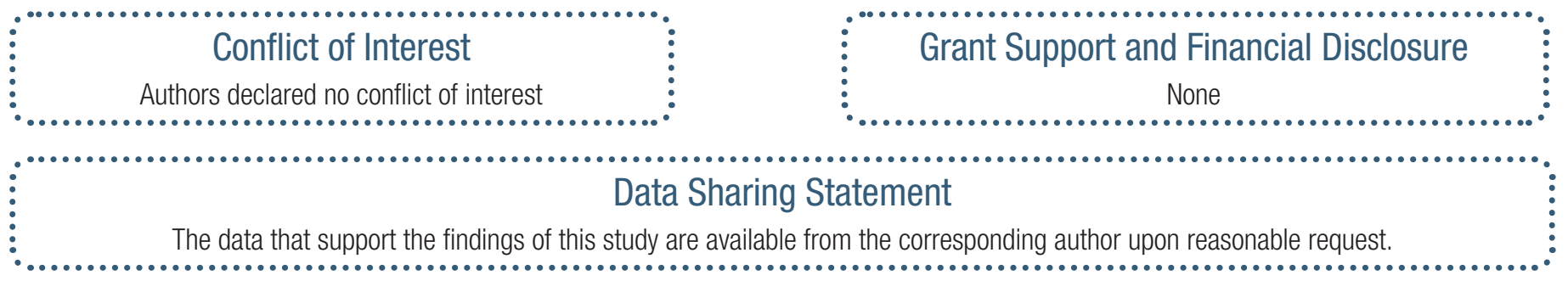

